\title{
Isolamento de Prototheca spp. de vacas com mastite, de leite de tanques de expansão e do ambiente dos animais ${ }^{1}$
}

\section{Isolation of Prototheca spp. from cows with mastitis, bulk tanks milk and in the environment of the animals}

\author{
Aline Artioli Machado Yamamura ${ }^{2 *}$; Ernst Eckehardt Müller ${ }^{3}$; \\ Lucienne Garcia Pretto-Giordano ${ }^{4}$; Mariana Cosenza ${ }^{5}$; \\ Patrícia Fernandes Nunes da Silva ${ }^{5}$; Agda de Godoy ${ }^{6}$
}

Resumo

\begin{abstract}
As infecções da glândula mamária de vacas leiteiras acarretam sérios prejuízos ao produtor pela diminuição da produção leiteira, tratamento e descarte de animais com infecções crônicas. Elevada incidência de mastite no rebanho também altera a composição e qualidade do leite. Agentes de mastite podem causar infecções ou intoxicações no homem. Nos últimos anos tem-se dado ênfase às infecções intramamárias por algas do gênero Prototheca, agentes de infecções persistentes e refratárias à terapêutica tradicional além do caráter zoonótico. Este trabalho teve como objetivo o isolamento e identificação de Prototheca spp. de amostras de leite coletadas em tanques de expansão e latões, de vacas com mastite e do ambiente dos animais. Foram coletadas 81 amostras de leite de tanques e latões de 81 propriedades. Prototheca zopfii foi identificada em amostras de tanques de 10 propriedades. Dessas propriedades foram estudadas oito quanto à ocorrência de Prototheca spp. no ambiente do rebanho e em casos de mastite, além da identificação dos principais agentes bacterianos causadores de mastite. Foram isoladas bactérias, algas e leveduras em 324 amostras de leite provenientes de 197 vacas. Em três propriedades foi isolada $P$. zopfii de onze amostras de leite obtidas de cinco vacas com mastite clínica e subclínica. Nestas propriedades o agente foi isolado do meio ambiente das vacas, fezes de bezerros e teteiras. Os resultados deste trabalho mostram a importância do isolamento no tanque como indicativo da presença de Prototheca spp. em propriedades leiteiras.
\end{abstract}

Palavras-chave: Mastite bovina, amostras de tanques, Prototheca zopfii

\begin{abstract}
The dairy cattle mammary gland infections cause serious economic losses to dairy farmers due to the decrease in milk production, therapeutic procedures and culling of chronic infected animals. High incidence of mastitis in herds also alters both the composition and the quality of the milk. Mastitis pathogens can also cause infections and poisoning in humans. In the last years, emphasis has been given to intramammary infections caused by the genus Prototheca which, besides their zoonotic
\end{abstract}

1 Parte de Tese de Doutorado apresentada pelo primeiro autor ao Curso de Pós-Graduação em Ciência Animal, Universidade Estadual de Londrina, Londrina - PR.

2 Professor Adjunto do Departamento de Medicina Veterinária Preventiva - UEL/CCA. Londrina - PR. E-mail: alineartioli@uel.br

3 Professor Titular do Departamento de Medicina Veterinária Preventiva -UEL/CCA, Londrina - PR.

4 Técnico de Nível Superior do Departamento de Medicina Veterinária Preventiva - UEL/CCA, Londrina - PR.

5 Aluno de Graduação do Curso de Medicina Veterinária e Zootecnia - UEL/CCA, Londrina - PR.

6 Médica Veterinária da Cooperativa CONFEPAR, Londrina - PR

* Autor para correspondência.

Recebido para publicação 14/09/06 Aprovado em 17/01/07 
characteristics, are considered mastitis pathogens of persistent infection and are refractory to traditional therapeutic procedures. The objective of this work was the isolation and identification of Prototheca spp. from milk samples collected from bulk tanks and milk cans, cows presenting mastitis and the dairy herd environment. Milk samples were collected from 81 bulk tanks and milk cans of 81 dairy herds. Prototheca zopfii was identified in milk samples in 10 dairy herds. From these, eight dairy herds were studied regarding Prototheca spp. mastitis and environmental occurrence as well as the main mastitis bacterial agents. Bacteria, algae and yeasts were isolated from 324 milk samples from 197 cows. P. zopfii was isolated in three dairy herds from eleven milk samples from five cows with clinical and subclinical mastitis. In these dairy herds with positive isolation of $P$. zopfii the agent was isolated from the herd environment, excrements of the calves and teat cup rubbers. The results of this work demonstrate the importance of isolation in bulk tanks as an indicative of Prototheca spp. presence in dairy herds.

Key words: Bovine mastitis, bulk tanks samples, Prototheca spp.

\section{Introdução}

Considerando a Instrução Normativa $\mathrm{n}^{\circ} 51$ de 18 de setembro de 2002 do Ministério da Agricultura, Pecuária e Abastecimento (BRASIL, 2002), que regulamenta a produção, transporte e processamento do leite, em vigor desde 1/7/2005, e a perspectiva do incremento na exportação de produtos lácteos, é necessário que produtores e indústria brasileira adotem medidas que visem à melhoria da qualidade do leite e derivados. As infecções da glândula mamária de vacas leiteiras causam grandes perdas ao produtor e à indústria de leite e derivados. Dentre os diferentes fatores que interferem na qualidade do leite e derivados destacam-se as infecções intramamárias. As mastites acarretam prejuízos decorrentes, principalmente, do descarte de animais com infecções crônicas, pela queda na produção de leite e pelas alterações na sua composição (NONNECKE; HARP, 1989).

Os agentes causadores da mastite são bactérias, fungos, algas e vírus, sendo as bactérias os agentes isolados com maior freqüência (COSTA, 1991). Com base na via de transmissão, os agentes etiológicos da mastite podem ser subdivididos em contagiosos e ambientais (NICKERSON, 1998). Os agentes contagiosos de maior importância são Staphylococcus aureus, Streptococcus agalactiae, Corynebacterium bovis e Mycoplasma spp. Os principais agentes ambientais são enterobactérias, estreptococos, actinomicetos, fungos e algas.
Nos últimos anos, foram relatadas com freqüência, no Brasil, mastites de origem ambiental causadas por algas aclorofiladas do gênero Prototheca, principalmente a espécie $P$. zopfii (COSTA et al., 1996a, 1997, 1998; MELVILLE, 1995; BENITES; MELVILLE; COSTA, 2003). No Estado do Paraná foram relados casos de mastite por Prototheca spp. na região Norte (FILLIPSEN et al., 1999; PARDO, et al., 1999; YAMAMURA et al., 2001). A mastite por Prototheca spp. pode ocorrer de forma esporádica ou na forma de surto no rebanho. A doença geralmente é de apresentação crônica e as vacas não respondem à terapia antimicrobiana tradicional. A secagem dos quartos mamários infectados ou o descarte das vacas acometidas é a medida adotada rotineiramente pelos produtores.

A Prototheca spp. é ubiqüitária, podendo ser encontrada no solo, na água, em fezes de diferentes espécies animais e equipamento de ordenha (MELVILLE, 1995). No homem a prototecose pode se manifestar sob várias formas clínicas, localizadas ou sistêmicas, sendo considerada uma zoonose (LEIMANN et al., 2004). Costa et al. (1998) relataram um caso de enterite no homem após ingestão de queijo fresco contaminado com $P$. zopfii.

Considerando o caráter zoonótico e a importante participação da $P$. zopfii na etiologia das mastites bovinas, este trabalho teve por objetivo o isolamento de Prototheca spp. em amostras de leite obtidas de tanques de expansão e latões, de vacas com mastite e do ambiente dos animais. 


\section{Material e Métodos}

Foram estudadas 81 amostras de leite obtidas diretamente dos tanques de expansão ou latões, por ocasião da coleta pelos caminhões com tanque isotérmico, de 81 propriedades leiteiras localizadas em oito municípios da região norte do Estado do Paraná. Nas propriedades pesquisadas, eram praticadas a ordenha mecânica ou manual e diferentes métodos de manejo e higiene da ordenha. Após homogeneização do leite foram colhidos de cada tanque ou latão aproximadamente $25 \mathrm{~mL}$ de leite, acondicionados em frascos de vidro esterilizados e transportados ao laboratório, em caixa isotérmica com gelo reciclável.

Das 10 propriedades com isolamento de Prototheca spp. nos tanques ou latões, oito foram visitadas novamente com a finalidade de isolar o agente em amostras de leite obtidas das vacas individualmente. Em duas leiterias a coleta de amostras individuais não foi possível. Nas oito propriedades estudadas detalhadamente, duas eram pequenas propriedades de subsistência, três com manejo a pasto, duas com sistema semi-intensivo e uma com sistema tie stall. Quatro propriedades produziam leite do tipo B e quatro do tipo C (Tabela 1). As propriedades apresentavam problemas no manejo, na higiene de ordenha e na manutenção do equipamento de ordenha. Duas propriedades realizavam ordenha manual em estábulo sem água corrente e com bezerro ao pé da vaca.

Foram coletadas 556 amostras de leite provenientes de 263 vacas com suspeita de mastite de um total de 433 vacas em lactação. As amostras foram coletadas das vacas com mastite clínica ou teste de Tamis positivo e de vacas reagentes ao CMT (Califórnia Mastitis Test) (SCHALM; NOORLANDER, 1957). A coleta foi realizada assepticamente em tubos de vidro, com tampa de rosca, esterilizados e transportados ao laboratório, em caixa isotérmica com gelo reciclável. Foram coletadas ainda, amostras de swabs retais de bezerros e vacas, swabs de teteiras e amostras de solo e água acondicionadas em frascos estéreis com capacidade para $30 \mathrm{~g}$ e $500 \mathrm{~mL}$, respectivamente. As amostras de solo de vários pontos do local foram coletadas com o auxílio de espátula estéril, $5,0 \mathrm{~cm}$ abaixo da superfície.

No laboratório de Micologia Veterinária do Departamento de Medicina Veterinária Preventiva da Universidade Estadual de Londrina $5 \mathrm{~mL}$ de leite colhidas de tanques ou latões foram adicionadas de $1 \mathrm{~mL}$ de Meio de Enriquecimento para Prototheca - MEP, contendo 5-fluorocitosina (PORE, R.; SHAHAN; PORE, M., 1987). Os frascos incubados a $32^{\circ} \mathrm{C}$ por aproximadamente 96 horas em estufaincubadora com plataforma de agitação. Alíquotas do meio de enriquecimento e amostras de leite obtidas de vacas individualmente, do solo, da água, das fezes e das teteiras foram semeadas por esgotamento em agar Sabouraud dextrose contendo $100 \mathrm{mg} / \mathrm{mL}$ de cloranfenicol e $0,1 \mathrm{~g} / \mathrm{L}$ de hidrocloreto de tiamina. As placas foram incubadas por 48 horas a $35^{\circ} \mathrm{C}$. Para a caracterização de gênero e espécie, as colônias foram identificadas conforme morfologia macro e microscópica, pela coloração com lactofenol-azulalgodão e rosa-de-bengala, e pela assimilação de carboidratos (sacarose, glicose e trealose) e de npropanol em meio YNB - Yeast Nitrogen Base (CAMARGO; FISCHMAN, 1979; PORE et al., 1983; PORE, 1985).

No laboratório de Bacteriologia Veterinária do Departamento de Medicina Veterinária da Universidade Estadual de Londrina foram processadas as amostras de leite para isolamento e identificação das principais bactérias causadoras de mastite. As amostras de leite foram semeadas e incubadas em agar-sangue ovino 5\% e agar MacConkey, em aerofilia por até 120 horas e 48 horas, respectivamente, e identificadas pelas características culturais, morfológicas, tintoriais e bioquímicas (KRIEG; HOLT, 1984; HARMON et al., 1990). 


\section{Resultados e Discussão}

Das 81 propriedades estudadas, foi isolada Prototheca spp. em 10 (12,3\%) propriedades, sendo que em sete a partir do tanque de expansão e em três de latões. Nas oito propriedades estudadas mais detalhadamente, duas eram pequenas propriedades de subsistência, três com manejo a pasto, duas com sistema semi-intensivo e uma com sistema tie stall. Quatro propriedades produziam leite tipo B e quatro do tipo C (Tabela 1). Todas as propriedades apresentavam problemas no manejo, na higiene de ordenha e na manutenção do equipamento de ordenha. Duas propriedades realizavam ordenha manual em estábulo sem água corrente e com bezerro ao pé da vaca.

Melville (1995) analisou no Brasil leite de tanques de expansão de 10 propriedades leiteiras por meio de plaqueamento direto das amostras e confirmou em quatro destas propriedades a presença de vacas com mastite por P. zopfii.

Um trabalho abrangente foi realizado por Pore, R., Shahan e Pore, M., (1987) nos EUA que pesquisaram 787 amostras compostas de leite obtidas dos quartos mamários das vacas e de tanques de expansão. Prototheca spp. foram isoladas do leite de 31 das 79 vacas amostradas em uma das propriedades, esses microrganismos também foram identificados em 28 das 787 amostras de leite coletadas nos tanques de expansão e de 22 das 69 amostras de leite obtidas de tanques de imersão. Além disso, esses mesmos autores desenvolveram e testaram um meio de enriquecimento que permitiu a obtenção de isolamento mais satisfatório de Prototheca spp. do leite coletado em tanques de expansão e caminhões-tanque, onde as amostras não são uniformes e o microrganismo pode ocorrer em número reduzido. O meio de enriquecimento desenvolvido pelos pesquisadores foi considerado eficaz de acordo com a análise estatística que confirmou não ser a $P$. zopfii considerada um microrganismo contaminante aleatório do leite composto dos tanques de expansão.
Segundo Brito et al. (1999), as questões individuais a serem respondidas em cada rebanho direcionam, em geral, o tipo e a quantidade de amostras de leite a serem avaliadas. Estas podem ser originadas de todas as vacas em lactação, somente dos casos clínicos, ou dos quartos mamários com contagens de células elevadas (ou com escores positivos no Califórnia Mastite Teste). Podem também representar amostras compostas dos quatro quartos mamários de uma vaca ou serem obtidas do leite dos tanques de expansão. Este último grupo de amostras tem por finalidade o monitoramento de rebanhos, detectam a presença de microrganismos patogênicos específicos e apresentam a vantagem de limitar custos com exames laboratoriais. A análise de amostras compostas dos quartos mamários é um método que diminui os custos com exames laboratoriais, no entanto, os referidos autores recomendam a colheita do leite de todos os quartos mamários das vacas em lactação e a cultura, que embora de custo mais elevado permite definir com mais exatidão os agentes infecciosos prevalentes no rebanho.

Os isolados de P. zopfii identificados no presente trabalho apresentam as seguintes características morfológicas, culturais e bioquímicas: colônias brancas, sulcadas, rugosas, de aspecto vítreo em agar Sabouraud; ao exame microscópico esporângios esféricos medindo de 14 a $25 \mu \mathrm{m}$ ou ovais com 11 a $20 \mu \mathrm{m}$ de largura por 14 a $23 \mu \mathrm{m}$ de comprimento, as células dauer coraramse seletivamente pelo corante rosa-de-bengala. Todas as cepas utilizaram glicose e n-propanol como fonte de carbono e não cresceram em presença de trealose e sacarose (PORE et al., 1983, PORE, 1985).

Das propriedades com isolamento de P. zopfii, duas apresentaram uma vaca com mastite subclínica. Em uma das propriedades com um rebanho de 80 vacas em lactação havia 30 com suspeita de mastite. A outra propriedade possuía um rebanho de 100 vacas em lactação com 52 suspeitas de mastite. Em uma leiteria com 61 vacas suspeitas de mastite, P. zopfii foi isolada em três vacas com mastite clínica e subclínica. Das cinco vacas com mastite por P. zopfii quatro possuíam os dois tetos afetados e uma os três tetos (Tabela 1). 
Tabela 1. Relação do número de vacas positivas ao exame microbiológico e para $P$. zopfii sobre número de amostras analisadas em associação ao sistema de manejo de oito propriedades leiteiras da região norte do Estado do Paraná com isolamento positivo de $P$. zopfii em amostras de leite de tanques de expansão e latões no período de abril de 2003 a novembro de 2004.

\begin{tabular}{|c|c|c|c|c|c|c|c|c|}
\hline \multirow[t]{2}{*}{$\begin{array}{l}\text { Propriedades } \\
\text { Leiteiras }\end{array}$} & \multirow[t]{2}{*}{$\begin{array}{l}N^{0} \text { de } \\
\text { vacas } \\
\text { em lactação }\end{array}$} & \multirow{2}{*}{\multicolumn{2}{|c|}{$\begin{array}{l}\mathbf{N}^{0} \text { de vacas positivas ao } \\
\text { exame microbiológico/ } \\
\mathbf{N}^{0} \text { de vacas suspeitas de } \\
\text { mastite } \\
\mathbf{N}^{\circ} \quad \text { (\%) }\end{array}$}} & \multicolumn{2}{|c|}{$\begin{array}{l}N^{\circ} \text { de amostras } \\
\text { positivas ao exame } \\
\text { microbiológico/ } N^{\circ} \text { de } \\
\text { amostras analisadas }\end{array}$} & \multirow{2}{*}{\multicolumn{2}{|c|}{$\begin{array}{l}\text { Relação do } \mathrm{n}^{0} \text { de } \\
\text { vacas positivas } \\
\text { para } P \text {. zopfii / } \\
\mathbf{n}^{0} \text { de vacas } \\
\text { suspeitas de } \\
\text { mastite }\end{array}$}} & \multirow{2}{*}{$\begin{array}{l}\mathbf{N}^{\circ} \text { de vacas } \\
\text { com mastite } \\
\text { por } P . \text { zopfii / } \\
\mathbf{n}^{\circ} \text { de tetos } \\
\text { com mastite } \\
\text { clínica e } \\
\text { subclínica }\end{array}$} \\
\hline & & & & $\mathbf{N}^{\mathbf{o}}$ & & & & \\
\hline 1* & 80 & $23 / 30$ & $(76,67)$ & $35 / 53$ & $(66,04)$ & $1 / 30$ & $(3,33)$ & 1/ 2 (subclínica) \\
\hline 2 & 25 & $17 / 17$ & $(100,0)$ & $37 / 49$ & $(75,51)$ & & - & - \\
\hline 3 & 78 & $52 / 57$ & $(91,22)$ & $93 / 116$ & $(80,17)$ & & - & - \\
\hline 4 & 10 & $8 / 10$ & $(80,00)$ & $13 / 21$ & $(61,90)$ & & - & - \\
\hline 5 & 19 & $9 / 19$ & $(47,36)$ & $13 / 29$ & $(44,83)$ & & - & - \\
\hline 6* & 100 & $33 / 52$ & $(63,46)$ & $45 / 114$ & $(39,47)$ & $1 / 52$ & $(1,92)$ & 1/ 2 (subclínica) \\
\hline 7 & 31 & $16 / 17$ & $(94,11)$ & $17 / 26$ & $(65,38)$ & & - & - \\
\hline $8^{*}$ & 90 & $39 / 61$ & $(63,93)$ & $71 / 148$ & $(47,97)$ & $3 / 61$ & $(4,92)$ & $\begin{array}{l}\text { 1/ } 2 \text { (subclínica) } \\
\text { 2/ } 5 \text { (clínica) }\end{array}$ \\
\hline Total & 433 & $197 / 2$ & & $324 / 55$ & & & $43(3,50)$ & $5 / 11$ \\
\hline
\end{tabular}

*Propriedades que apresentaram vacas com mastite por P. zopfii, leite do tipo B, com sistema de manejo: 1. tie stall, 2. e 3. semi-intensivo.

Os primeiros relatos de mastite por Prototheca spp., freqüentemente estavam associados a casos clínicos (FRANK et al., 1969). Nos últimos anos, porém, os trabalhos têm mostrado uma ocorrência cada vez mais elevada de casos subclínicos (COSTA et al., 1995, 1996b; ABARCA et al., 2001). Além das duas formas de apresentação da doença causarem redução significativa na produção de leite, a infecção pode persistir no período seco ou ocorrerem novas infecções que não permitem a regeneração adequada da glândula mamária, comprometendo a próxima lactação com redução na produção de leite do animal (CORBELLINI et al., 2001).

A literatura registra casos esporádicos de mastite por Prototheca spp. com certa freqüência em vários países, inclusive no Brasil (COSTA et al., 1996b; BRITO; VEIGA, 1997; MALINOWSKI; LASSA; KLOSSOWSKA, 2002; BUZZINI et al., 2004). Melville (1995), pesquisando amostras de tanque e de vacas individualmente, encontrou uma baixa porcentagem de vacas acometidas por $P$. zopfii nos rebanhos estudados. No entanto, relatos de surtos com elevada porcentagem de animais acometidos por Prototheca spp. têm ocorrido com certa freqüência.
Hodges et al. (1985) descreveram um surto na Nova Zelândia com 17 vacas infectadas, de um total de 120 animais. Costa et al., (1996b) observaram em uma propriedade taxas $14,95 \%$ e $8,06 \%$ de mastite por Prototheca spp. nas vacas em lactação e nas vacas secas, respectivamente.

Nas propriedades que apresentaram vacas com mastite por P. zopfii, o agente foi isolado em pelo menos um dos seguintes locais ou amostras com alta umidade e ricos em matéria orgânica: solo de piquetes (2), solo de pastagem (1), água de abastecimento (1), esgoto (1), fezes de bezerros (1) e das teteiras entre a ordenha de uma vaca e outra (3).

Hodges et al. (1985), Anderson e Walker (1988) e Costa et al. (1997) relataram o isolamento de Prototheca spp. do meio ambiente das vacas leiteiras e do solo úmido e rico em matéria orgânica, sendo os locais mais citados: piquetes, água e cama dos animais. Anderson e Walker (1988), em uma propriedade com 263 vacas em lactação, isolaram Prototheca spp. em 18 (47\%) das amostras de meio ambiente e em fezes dos animais. Na mesma propriedade obtiveram o isolamento de Prototheca spp. de uma amostra de leite do tanque de expansão e 
quatro vacas com mastite que não responderam à terapia convencional. Yamamura et al. (2003) demonstraram por meio do isolamento de Prototheca spp. de amostras de fezes de bezerros e suínos, de teteiras e de água servida do piso de sala de ordenha, de propriedade leiteira no Estado do Paraná com surto de mastite bovina causada por P. zopfii, que o ambiente dos animais pode ser considerado via de transmissão da infecção intramamária.

As oito propriedades leiteiras estudadas apresentaram 197 vacas positivas no exame microbiológico com isolamento de bactérias, algas e leveduras isoladas de 324 quartos mamários (Tabela 2).

Tabela 2. Microrganismos isolados de 324 quartos mamários de 197 vacas com suspeita de mastite clínica ou subclínica em oito propriedades leiteiras com isolamento de Prototheca spp. em amostras de leite de tanques de expansão e latões do norte do Estado do Paraná, nos anos de 2003 e 2004.

\begin{tabular}{|c|c|c|}
\hline \multirow{2}{*}{ Microrganismos } & \multicolumn{2}{|c|}{ Quartos afetados } \\
\hline & $\mathbf{N}$ & $(\%)$ \\
\hline Corynebacterium bovis & 106 & $(32,72)$ \\
\hline Staphylococcus coagulase (-) & 93 & $(28,70)$ \\
\hline Streptococcus spp. & 39 & $(12,03)$ \\
\hline Staphylococcus coagulase $(+)$ & 32 & $(9,88)$ \\
\hline Staphylococcus coagulase (-) + Corynebacterium bovis & 13 & $(4,01)$ \\
\hline Candida spp. & 11 & $(3,39)$ \\
\hline Prototheca zopfii & 8 & $(2,47)$ \\
\hline Prototheca zopfii + Candida spp. & 2 & $(0,62)$ \\
\hline Prototheca zopfii + Staphylococcus coagulase (-) & 1 & $(0,31)$ \\
\hline Staphylococcus coagulase (-) + Streptococcus spp & 6 & $(1,85)$ \\
\hline Streptococcus spp. + Corynebacterium bovis & 5 & $(1,54)$ \\
\hline Staphylococcus coagulase (-) + Streptococcus spp. + Corynebacterium bovis & 2 & $(0,62)$ \\
\hline Streptococcus spp. + Corynebacterium bovis + Candida spp. & 1 & $(0,31)$ \\
\hline Staphylococcus coagulase (-)+ Corynebacterium bovis + Candida spp. & 1 & $(0,31)$ \\
\hline Staphylococcus coagulase (-) + Staphylococcus coagulase $(+)$ & 1 & $(0,31)$ \\
\hline Staphylococcus coagulase $(+)+$ Candida spp. & 1 & $(0,31)$ \\
\hline Staphylococcus coagulase (-) + Candida spp. & 1 & $(0,31)$ \\
\hline Pseudomonas aeruginosa & 1 & $(0,31)$ \\
\hline Total de quartos examinados & 324 & $(100,0)$ \\
\hline
\end{tabular}

A predominância de agentes contagiosos (C. bovis e Staphylococcus coagulase positivo) mostra as deficiências de manejo, higiene de ordenha e manutenção inadequada dos equipamentos de ordenha. Por outro lado, a elevada porcentagem de agentes ambientais isolados (Streptococcus spp., leveduras e $P$. zopfii) mostra a existência de problemas relativos ao ambiente das vacas. As deficiências de manejo de ordenha e condições ambientais impróprias podem ser comprovadas pela elevada porcentagem de animais com mastite clínica ou subclínica nestes rebanhos. Do total de 433 vacas em lactação, 197 (45,5\%) apresentaram resultados microbiológicos positivos. Estes fatos podem justificar o isolamento de Prototheca spp. no leite de amostras compostas e individuais já que altas taxas de mastite, tratamentos intramamários prévios e condições ambientais inadequadas podem favorecer novas infecções por este agente.

Este trabalho mostra que Prototheca spp. pode ser isolada de amostras de leite individuais e tanques de expansão ou latões de propriedades leiteiras com 
ou sem histórico de mastite. Pore, R., Shahan e Pore, M. (1987) e Baumgärtner (1997) também observaram estes resultados. O isolamento de P. zopfii de amostras de leite de tanque, mesmo em propriedades sem casos aparentes de mastite, indica a possibilidade de contaminação do leite e derivados e conseqüente possibilidade de infecções humanas por Prototheca zopfii. Melville (1995) avaliou a resistência de diferentes culturas de $P$. zopfii a diferentes processos térmicos, concluíram que muitas permaneceram viáveis após a pasteurização e afirmaram que o leite e seus derivados representam fonte potencial de transmissão desta zoonose. Este fato foi constatado por Costa et al. (1998) que relataram um caso de distúrbio gastrointestinal em um homem que ingeriu voluntariamente queijo fresco contaminado por Prototheca spp. Pessoas com deficiências imunológicas ou desnutridas são mais suscetíveis à infecção (KLINTWORTH; FETTER; NIELSEN, JR., 1968; CAREY et al., 1997; MOHABEER et al., 1997).

\section{Conclusões}

O isolamento de P. zopfii de tanques de expansão e latões permitiu confirmar a existência de casos de mastite clínica e subclínica, assim como a sua presença no ambiente em três propriedades leiteiras dentre oito analisadas.

Isolamento de $P$. zopfii de amostras de leite individuais e de tanques de expansão e latões de propriedades leiteiras, com ou sem histórico de mastite por este microrganismo, pode indicar contaminação do equipamento de ordenha e dos recipientes de armazenamento do leite, associados à manutenção inadequada do equipamento de ordenha e às deficiências de manejo e higiene.

Os resultados desta pesquisa permitem sugerir, devido à importância de $P$. zopfii em saúde pública, que a triagem em tanques de expansão poderia ser utilizada como diagnóstico de rotina em propriedades leiteiras.

\section{Agradecimentos}

Ao Dr Newton Barbosa do setor de farmácia do Hospital Universitário da Universidade Estadual de Londrina que gentilmente forneceu o antifúngico utilizado no meio seletivo.

Ao Dr. Newton Kimura, Médico Veterinário e Presidente da Cooperativa COLARI, por permitir a colheita de amostras de leite de tanques de expansão nas propriedades leiteiras atendidas pela cooperativa.

Aos Senhores Ilson e Erich, funcionários da COLARI, pela colaboração na colheita das amostras dos tanques de expansão nas propriedades das regiões de Maringá e Rolândia.

\section{Referências}

ABARCA, M. L.; BUENO, L.; TORRE, E.; CABAÑES, F. J. Subclinical bovine mastitis by Prototheca zopfii in Spain. Journale de Mycologie Médicale, Paris, v.11, n.3, p.159160, 2001.

ANDERSON, K. L.; WALKER, R. L. Sources of Prototheca spp in a dairy herd environment. Journal of American Veterinary Medical Association, Schaumburg, v.193, n.5, p.553-556, 1988.

BAUMGÄRTNER, B. Vorkommen und bekämpfung der prototheken-mastitis dês rindes im einzugsgebien des staatlichen veterinär-und lebensmitteluntersuchungsamtes. Der Praktische Tierärztliche, Potsdam, n.78, p.406-414, 1997.

BENITES, N. R.; MELVILle, P. A.; COSTA, E. O. Evaluation of the microbiological status of milk and various strutures in mammaru glands from naturally infected dairy cows. Tropical Animal Health and Production, Dordrecht, v.35, n.4, p.301-307, 2003.

BRASIL. Ministério de Estado da Agricultura, Pecuária e Abastecimento. Regulamento da inspeção industrial e sanitária de produtos de origem animal: instrução normativa $n^{\circ} 51$, de 18-9-2002. Art. $1^{\circ}$. Aprovar os regulamentos técnicos de produção, identidade e qualidade do leite tipo A, do leite tipo B, do leite tipo C, do leite pasteurizado e do leite cru refrigerado e o regulamento técnico da coleta de leite cru refrigerado e seu transporte a granel, em conformidade com os anexos a esta instrução normativa. Brasília: Ministério da Agricultura, 2002. 
BRITO, M. A. V. P.; VEIGA, V. M. O. Mastite bovina causada por Prototheca zopfii. Relato de um caso. Ciência Rural, Santa Maria, v.27, n.4, p.681-684, 1997.

BRITO, M. A. V. P.; BRITO, J. R. F.; RIBEIRO, M. T.; VEIGA, V. M. O. Padrão de infecção intramamária em rebanhos leiteiros: exame de todos os quartos mamários das vacas em lactação. Arquivo Brasileiro de Medicina Veterinária e Zootecnia, Belo Horizonte, v.51, n.2, p.129135, 1999.

BUZZINI, P.; TUCHETTI, B.; FACELLI, R.; BAUDINO, R.; CARERO, F.; MATTALIA, L.; MOSSO, P.; MARTINI, A. First large-scale isolation of Prototheca zopfii from milk produced by dairy herds in Italy. Mycopathologia, Netherlands, v.158, n. 4, p.427-430, 2004.

CAREY, W. P.; KAYKOVA, Y.; BANDRES, J. C.; SIDHU, G. S.; BRÄU, N. Cutaneous protothecosis in a patient with AIDS and a severe functional neutrophil defect: successful therapy with amphotericin B. Clinical Infectious Diseases, Chicago, n.25, p.1265-1266, 1997.

CAMARGO, Z. P.; FISCHMAN, O. Use of morphophysiological characteristics for differentiation of the species of Prototheca. Sabouraudia, England, v.17, p.275$278,1979$.

CORBELLINI, L. G.; ORLEMEIER, D.; CRUZ, C.; DIAS, M. M.; FERREIRO, L. Bovine mastitis due to Prototheca zopfii: clinical, epidemiological and pathological aspects in a Brazilian dairy herd. Tropical Animal Health and Production, Netherlands, v.6, n.33, p.463-473, 2001.

COSTA, E. O. Importância econômica da mastite infecciosa bovina. Revista da Faculdade de Medicina Veterinária e Zootecnia da Universidade de São Paulo, São Paulo, v.1,p.21-26, 1991.

COSTA, E. O.; BENITES, N. R.; MELVILLE, P. A.; PARDO, R. B.; RIBEIRO, A. R.; WATANABE, E. T. Estudo etiológico da mastite clínica bovina. Revista Brasileira de Medicina Veterinária, Rio de Janeiro, v.17, n.4, p.156$158,1995$.

COSTA, E. O.; RIBEIRO, A. R.; WATANABE, E. T.; PARDO, R. B.; SILVA, J. B.; SANCHES, R. B. An increased incidence of mastitis caused by Prototheca species and Nocardia species on a farm in São Paulo, Brazil. Veterinary Research Communications, Netherlands, v.20, p.237-241, $1996 \mathrm{a}$

COSTA, E. O.; RIBEIRO, A. R.; MELVILLE, P. A.; PRADA, M. S. CARCIOFI, A. C.; WATANABE, E. T. Bovine mastitis due to algae of the genus Prototheca. Mycopathologia, Netherlands, v.133, p.85-88, 1996 b.
COSTA, E. O.; MELVILlE, P. A.; RIBEIRO, A. R.; WATANABE, E. T.; PAROLARI, M. C. F. F. Epidemiologic study of environmental sources in a Prototheca zopfii outbreak of bovine mastitis. Mycopathologia, Netherlands, v.137, p.33-36, 1997.

COSTA, E. O., MELVILle, P. A., RIBEIRO, A. R., WATANABE, E. T. Relato de um caso de consumo de queijo fresco contaminado com Prototheca spp. Revista do Núcleo de Apoio à Pesquisa em Glândula Mamária e Produção Leiteira, São Paulo, v.1, n.1, p.9-19, 1998.

FILLIPSEN, L. F.; MOREIRA, F. B.; SAKASHITA, A. T.; BITTENCOURT, D. R. Prevalência da mastite bovina causada por Prototheca zopfii em rebanhos leiteiros, na região Norte do Estado do Paraná. Ciência Rural, Santa Maria, v.29, n.1, p.87-89, 1999.

FRANK, N.; FERGUSON, L. C.; CROSS, R. F.; REDMAN, D. R. Prototheca, a cause of bovine mastitis. American Journal of Veterinary Research, Chicago, v.30, n.10, p.1785-1794, 1969.

HARMON, R. J.; EBERHART, R. J.; JASPER, D. E.; LANGLOIS, B. E.; WISLON, R. A. Microbiological procedures for diagnosis of bovine udder infection. Arlington: National Mastitis Council, 1990.

HODGES, R. T.; HOLLAND, J. T. S.; NEILSON, F. J. A.; WALLACE, N. M. Prototheca zopfii mastitis in a herd of dairy cows. New Zealand Veterinary Journal, Palmerton North, v.33, n.7, p.108-111, 1985.

KLINTWORTH, G. K.; FETTER, B. F.; NIELSEN, H. S. Protothecosis, an algal infection: report of a case in man. The Journal of Medical Microbiology, Edinburgh, v.1, p.211-215, 1968 .

KRIEG, N. R.; HOLT, J. G. Bergey's manual of systematic bacteriology. $9^{\text {th }}$ ed. Baltimore: Williams \& Wilkins, 1984.

LEIMANN, B. C. Q.; MONTEIRO, P. C .F.; LAZÉRA, M.; CANDANOZA, E. R. U.; WANKE, B. Protothecosis: case report and literature review. Medical Mycology, Abingdon, v.42, n.2, p.95-106, 2004.

MALINOWSKI, E.; LASSA, H.; KLOSSOWSKA, A. Isolation of Prototheca zopfii from inflamed secretion of udders. Bulletin of the Veterinary Institute in Pulawy, Pulawy, v.46, n.2, p.295-299, 2002.

MELVILLE, P. A. Estudos sobre algas do gênero Prototheca isoladas de leite e de infecções intramamárias em bovinos leiteiros. 1995. Dissertação (Mestrado em Microbiologia) - Universidade de São Paulo, São Paulo.

MOHABEER, A. J.; KAPLAN, P. J.; SOUTHERN, JR., P. GANDER, R. M. Algaemia due to Prototheca wickerhamii in a patient with myasthenia gravis. Journal of Clinical Microbiology, Washington, v.35, n.12, p.3305-3307, 1997. 
NICKERSON, S. C. Estratégias para controlar a mastite bovina. In: SIMPÓSIO INTERNACIONAL SOBRE QUALIDADE DO LEITE, 1., 1998, Curitiba, PR, Anais... Curitiba: Associação Paranaense de Criadores de Bovinos da Raça Holandesa/UFPR, 1998. p.20-27.

NONNECKE, B. J.; HARP; J. A. Function and regulation of lymphocyte: mediated immune responses: relevance to bovine mastitis. Journal of Dairy Science, Savoy, v.72, p.1313-1317, 1989.

PARDO, R. B.; CHAVES NETO, R. C.; FERNANDES, G. D.; DUARTE, D. D. S.; FERNANDES, A. A.; YOKOSAWA, S. Y.; MENCK, R. G.; GODOY, C. A.; FARINAZZO, A. M. Levantamento dos agentes etiológicos da mastite bovina na região de Arapongas, PR: resultados preliminares. In: ENCONTRO DE PESQUISADORES EM MASTITES, 3. 1999, Botucatu, SP, Anais... Botucatu: |Universidade Estadual de São Paulo - Faculdade de Medicina Veterinária e Zootecnia, 1999. p.159.

PORE, R. S.; BARNETT, E. A.; BARNES, JR, W. C.; WALKER, J. D. Prototheca ecology. Mycopathologia, Netherlands, v.81, p.49-62, 1983.

PORE, R. S. Prototheca taxonomy. Mycopathologia, Netherlands, v.90, p.29-139, 1985.
PORE, R. S.; SHAHAN, T. A.; PORE, M. D. Occurrence of Prototheca zopfii, a mastitis pathogen in milk. Veterinary Microbiology, Amsterdam, v.15, p.315-324, 1987.

SCHALM, O. W.; NOORLANDER, D. O. Experimental and observation leading to development of California mastitis test. Journal of American Veterinary Medical Association, Schaumburg, n.139, p.199-204, 1957.

YAMAMURA, A. A. M.; SHIMADA, M. K.; MÜLLER, E. E.; FREITAS, J. C.; GIORDANO-PRETTO, L. G.; PEREIRA, E. C. Ocorrência da mastite por algas do gênero Prototheca na região de Londrina, Estado do Paraná. In: CONGRESSO BRASILEIRO DE MICOLOGIA, 3., 2001, Águas de Lindóia, SP, Anais... Águas de Lindóia: Sociedade Brasileira de Micologia, 2001, p.123.

YAMAMURA, A. M. M.; MÜLLER, E. E.; PRETTOGIORDANO, L. G.; NOGUEIRA, R.; NUNES, P. Surto de mastite bovina por algas do gênero Prototheca e detecção de fontes de infecção em uma propriedade leiteira. In: CONGRESSO BRASILEIRO DE MICROBIOLOGIA, 22. 2003, Florianópolis, SC, Anais...Florianópolis: Sociedade Brasileira de Microbiologia, 2003, p.225. 